\title{
Assessment of the Impact of Abattoir Effluent on the Water Quality of River Kaduna, Nigeria
}

\author{
Terrumun Kenneth Kwadzah, Oliver Terna Iorhemen* \\ Department of Agricultural and Environmental Engineering, University of Agriculture, Makurdi, Nigeria \\ *Corresponding author: iorhemen.terna@uam.edu.ng
}

Received June 30, 2015; Revised August 07, 2015; Accepted October 14, 2015

\begin{abstract}
The discharge of untreated high-strength wastewater into water bodies results in water quality deterioration of the receiving waters. The aim of this study was to assess the impact of abattoir wastewater discharge on the water quality of river Kaduna, Nigeria. Water samples were collected from river Kaduna at three points: $100 \mathrm{~m}$ upstream of the abattoir discharge point, at the discharge point, and $100 \mathrm{~m}$ downstream of the discharge point for a 6-month period (July- September in the rainy season and October-December in the dry season). Physicochemical analyses were conducted on the collected samples in the laboratory using standard methods. The $\mathrm{pH}$ was within a fixed band of 6-8. The downstream 5-day biochemical oxygen demand of the receiving river water increased significantly to $75 \%$ in July and up to $192 \%$ in December. Suspended solids, chemical oxygen demand, ammonia-nitrogen, total nitrogen and total phosphorus followed a similar trend. Dissolved solids, dissolved oxygen, nitrate- $\mathrm{N}$, iron, zinc and cadmium also increased appreciably. The downstream levels of these parameters were higher than their corresponding upstream values, indicating that the discharge of the abattoir wastewater into the river has negatively impacted the river water. The dilution of the waste in the river water was not enough to reduce them to acceptable levels. This research demonstrates that abattoir wastewater impacts the river water negatively. The findings can be useful in identifying water quality problem areas and planning of engineering interventions as well as basis for legislation.
\end{abstract}

Keywords: abattoir wastewater, impact, river Kaduna, pollution, water quality

Cite This Article: Terrumun Kenneth Kwadzah, and Oliver Terna Iorhemen, "Assessment of the Impact of Abattoir Effluent on the Water Quality of River Kaduna, Nigeria." World Journal of Environmental Engineering, vol. 3, no. 3 (2015): 87-94. doi: 10.12691/wjee-3-3-3.

\section{Introduction}

The discharge of untreated wastewater into surface water bodies such as streams, rivers, lakes and oceans results in the pollution of such water environments. This pollution of surface water bodies, resulting from anthropogenic activities, is a growing concern worldwide $[1,2]$. The elevated levels of nutrients (nitrogen and phosphorus) in surface water due to pollution accelerate the growth of oxygen-depleting microbes, destroy the aquatic ecosystems and result in eutrophication [3]. Eutrophication causes many adverse effects on the water body including increased biomass of phytoplankton and macrophyte vegetation, increased blooms of gelatinous zooplankton (marine environment), growth of benthic and epiphytic algae, increased toxins from bloom-forming algal species, loss of commercial and sport fisheries, reduced carbon available to food webs, increased taste and odour problems, reduced species diversity, increased treatment costs prior to human use, and decreased aesthetic value of the water body [4,5].

In Nigeria, many streams and rivers get polluted as a result of the discharge of untreated wastewater and other organic wastes directly into them $[6,7,8]$. Thus, river pollution is becoming a central issue in water management in Nigeria [9]. One of the major sources of river pollution is livestock production activities [10] especially in terms of nutrient pollution [11]. Animal faeces and urine can be a source of pollution if not properly managed. If the animals are not housed, there may also be issues of erosion and sediment transport into surface waters due to their grazing activities. The runoff of animal wastes into surface water poses a great risk of pollution [12]. The waste from abattoirs, where the animals are slaughtered, pose another risk due to its high biochemical oxygen demand (BOD), nutrients and pathogens content $[13,14]$.

The location of abattoirs in Nigeria tend to be near water bodies for easy access to guaranteed water for processing activities [15]. The wastewater generated from the various abattoir activities - abattoir wastewater typically comprises water generated from cleaning operations, animal blood, dissolved solids, oil and grease, gut contents, and urine $[16,17]$. The contamination of surface water from abattoir wastewater constitute significant environmental and health hazards [18] due the elevated levels of biodegradable organic matter, sufficient alkalinity, and adequate phosphorous, nitrogen and micronutrient concentrations [17].

In Kaduna metropolis, the abattoir wastewater at Tudun Wada Abattoir is conveyed via a natural channel called 
'blood river' to discharge directly into River Kaduna without any form of treatment. While some organic waste can be diluted in the river to very low concentration and subsequently self-cleansed by natural biological processes in the river, high strength wastes like abattoir wastewater may take a longer time to degrade. Some waste may not biodegrade at all depending on the chemical oxygen demand (COD) to BOD ratio [19].

Thus, the aim of this research was to estimate the extent of surface water pollution arising from the runoff and direct disposal of the abattoir wastewater into river Kaduna through water quality monitoring.

\section{Materials and Methods}

\subsection{Description of Study Area}

The study was conducted on river Kaduna around Tudun Wada abattoir area of Kaduna metropolis, Kaduna State, Nigeria. Tudun Wada lies between latitudes $10^{\circ} 28^{\prime}$ $14 " \mathrm{~N}$ and $10^{\circ} 30^{\prime} 45^{\prime \prime} \mathrm{N}$; and between longitudes $7^{\circ} 24^{\prime}$ $40^{\prime \prime} \mathrm{E}$ and $7^{\circ} 26^{\prime} 50^{\prime \prime E}$. Figure 1 below presents a map of the study area.

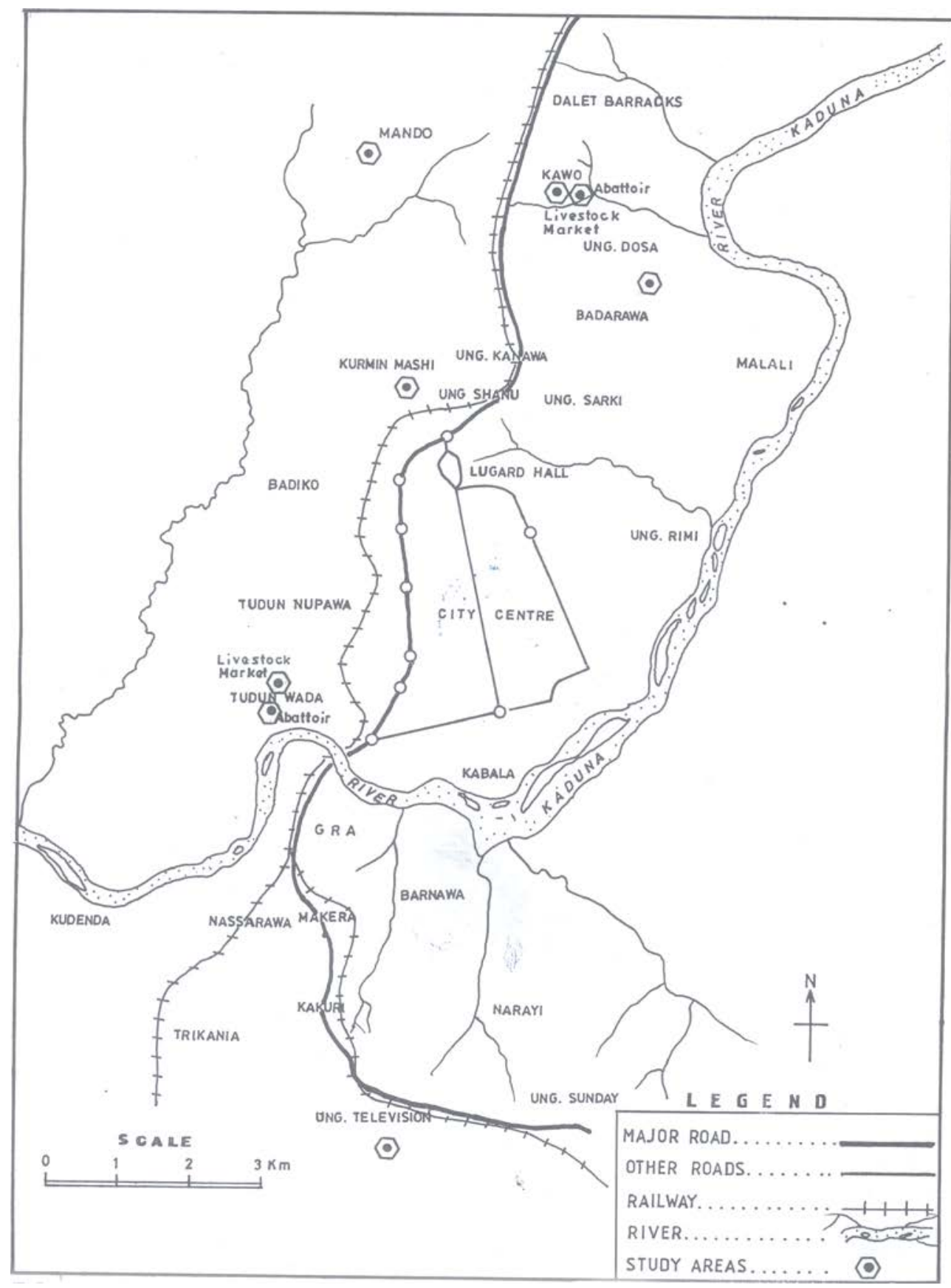

Figure 1. Map of the study area

\subsection{Water Sampling}

Grab water samples were collected from river Kaduna at three points: $100 \mathrm{~m}$ upstream of the abattoir discharge point on river Kaduna (TAUS), at the discharge point (TADP), and $100 \mathrm{~m}$ downstream of the discharge point
(TADS). The water samples were collected in 1-litre plastic bottles held in the middle and immersed about 10$20 \mathrm{~cm}$ in water against flow [20]. The collected samples were taken to the laboratory for analyses. The collection of samples was done for a period of six consecutive months to capture water quality trends in the rainy season 
months of July to September, and dry season months of October to December. All the samples collected were transported to the laboratory and analyzed within 2 hours of collection.

\subsection{Laboratory Analyses}

Physico-chemical tests were conducted on the collected samples in the laboratory. The following physical parameters were measured: $\mathrm{pH}$, temperature, conductivity, total suspended solids (TSS) and total dissolved solids (TDS). Chemical parameters measured include: dissolved oxygen (DO), 5-day biochemical oxygen demand $\left(\mathrm{BOD}_{5}\right)$, COD, nitrate-nitrogen, ammonia-nitrogen, total nitrogen, and total phosphorus. BOD and COD are known to be indicators of organic pollution in water [21]. The water samples were also tested for the following heavy metals: iron, zinc, lead and cadmium.

\subsection{Methods of Analyses}

The $\mathrm{pH}$ and temperature were analyzed in situ using Henna $\mathrm{pH} /$ temperature meter while conductivity, TSS and TDS were analyzed in the laboratory using standard methods. Chemical analyses were conducted in the laboratory according to the Standard Methods for the Examination of Water and Wastewater [20]. The determination of heavy metals was carried out by atomic absorption spectrophotometer techniques (Perkin-Elmer model 3110 equipped with HG500 graphite furnace), in flame or flameless mode, depending on element.

\section{Results and Discussions}

\subsection{Physical Parameters}

This section presents results of the physical parameters tested on the water samples. The results are accompanied by discussion. In the results figures, TADP stands for water samples collected from the Tudun Wada abattoir discharged point on river Kaduna, TAUS stands for water samples collected from river Kaduna 100m upstream of the abattoir discharge point, and TADS stands for water samples collected from river Kaduna 100m downstream of the abattoir discharge point.

\subsubsection{Temperature and $\mathrm{pH}$}

The temperature and $\mathrm{pH}$ variation during the study period are presented in Figure 2 and Figure 3 below.

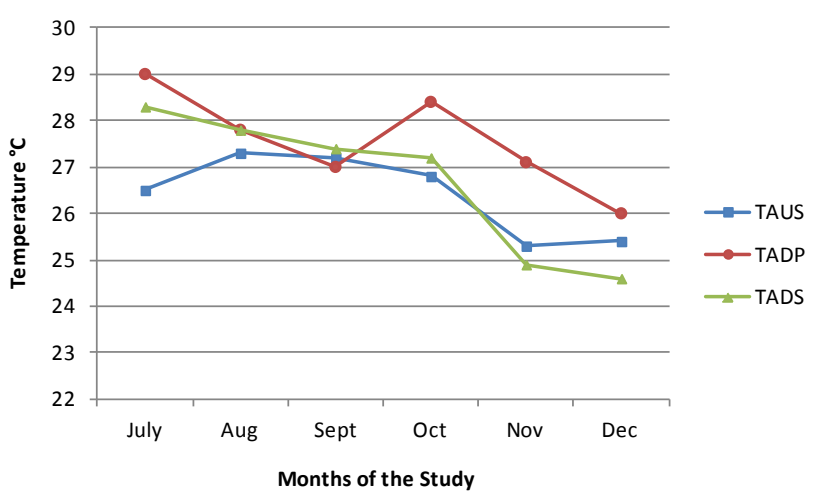

Figure 2. Temperature trend during the study period

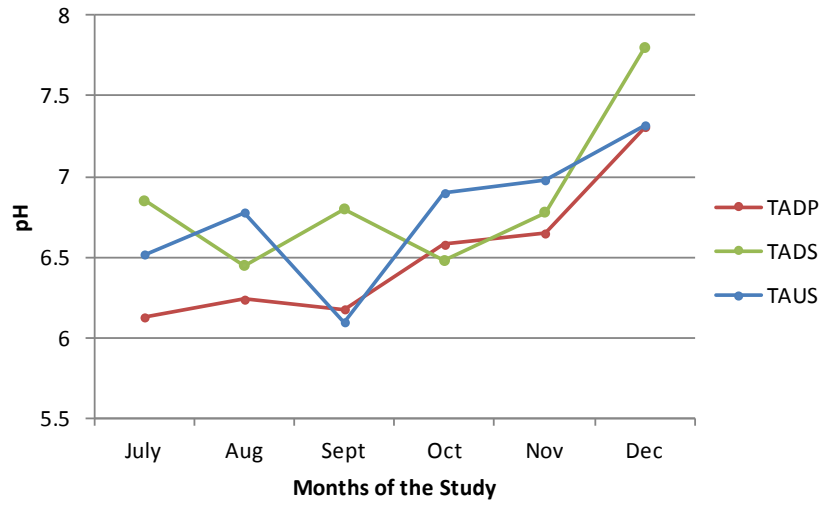

Figure 3. Variation of $\mathrm{pH}$ during study the period

The temperature decreased evenly towards the harmattan months of October, November and December. This is expected as the weather is usually cooler due to the dry cold North-easterly wind and dust clouds that screen most of the radiation. As with $\mathrm{pH}$, there is no pattern of temperature variation between the three sample collection points.

From Figure 3, the $\mathrm{pH}$ values fluctuated from month to month within a fixed band of 6-8. There is no pattern of $\mathrm{pH}$ variation between the three sample collection points. Peak values were experienced in November and December. This could be as a result of the increase in algae populations (which made the water greenish in color) by their photosynthetic activity which could have increased the number of hydroxyl ions [22]. Most pH values are within the world health organization (WHO) recommended range of $\mathrm{pH}$ values $(6.5$ - 8.5) for even drinking water [23].

\subsubsection{Conductivity}

The variation in conductivity of the collected samples is presented in Figure 4 below.

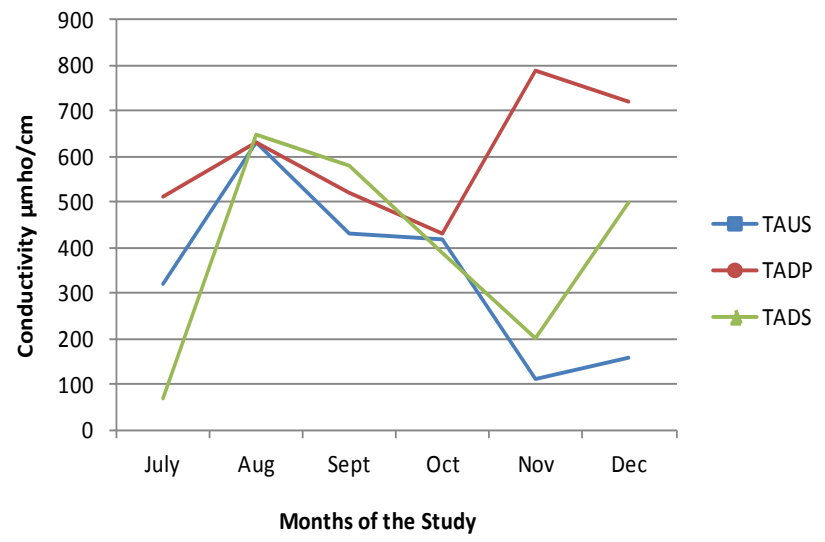

Figure 4. Variation of conductivity during study the period

Conductivity varied irregularly within the study period. This was expected as conductivity is related to the total dissolved solids in the water.

\subsubsection{Solids}

Figure 5 and Figure 6 below present the total suspended solids (TSS) and total dissolved solids (TDS) respectively.

Figure 5 shows a continuous increase of TSS month after month within the study periods. This is attributable to increased runoff inflow from the catchment area from 
the month of July to August, and reduced dilution of the river water from October to December when there is no more rainfall.

Figure 6 indicates high TDS values in the rainy months of August, September and early October with August and September recording the highest values. This agrees with earlier findings reported [24] and can be attributed to the increased inflow of surface runoff volume during those months. TDS values obtained were generally below the $1000 \mathrm{mg} / \mathrm{L}$ upper limit set by WHO above which water becomes significantly and increasingly unpalatable [23].

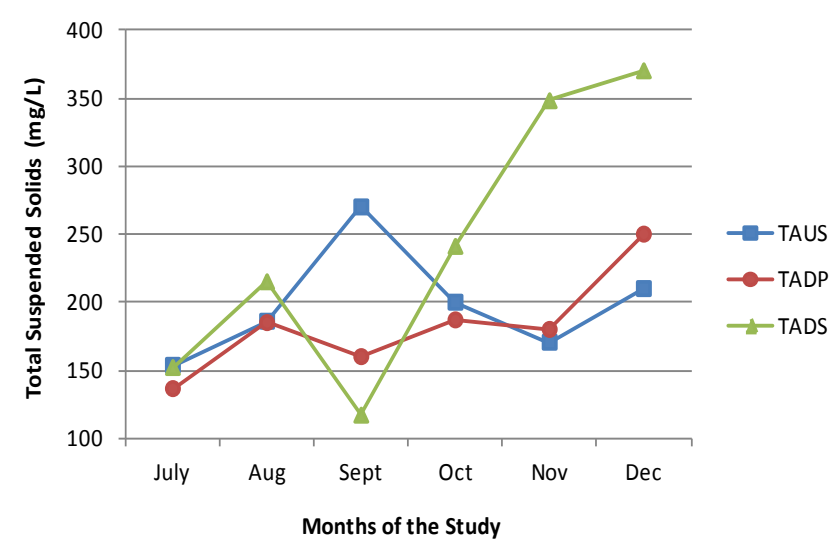

Figure 5. Total suspended solids trend during the study period

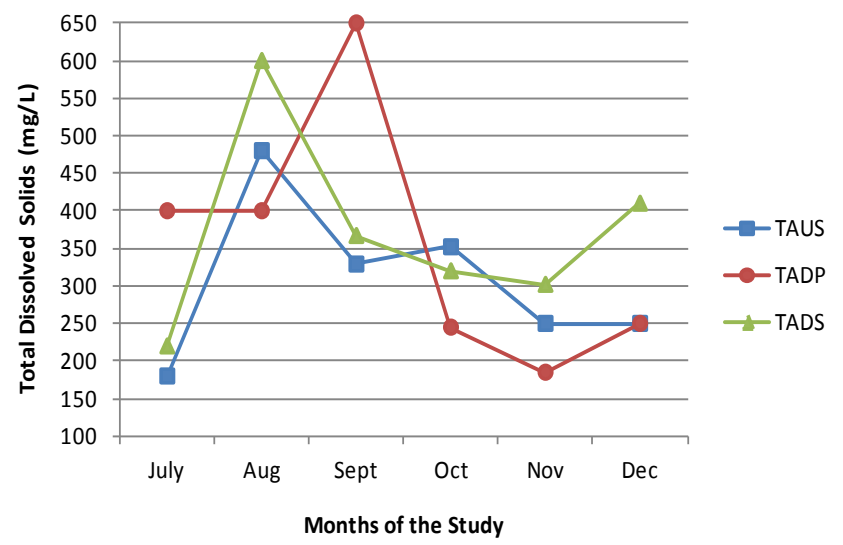

Figure 6. Total dissolved solids trend during the study period

\subsection{Chemical parameters}

\subsubsection{Dissolved Oxygen}

The results for dissolved oxygen levels within the study period are presented in Figure 7 below.

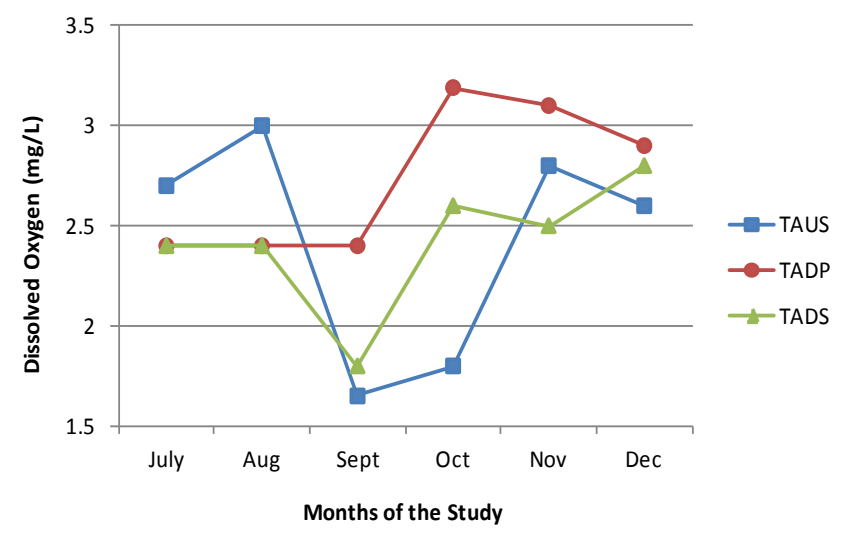

Figure 7. Variation of dissolved oxygen during study the period
From Figure 7, there is a peak experienced for the last three months of the study period. This could be as a result of the absence of the runoff component of organic matter from the catchments, lower temperatures as a result of harmattan fog as well as wind-induced mixing due to increased wind speed within the period. The sag in the dissolved oxygen in September is attributable to the fact that samples collection was carried out under rain, samples may have included bottom sediments as a result of the turbulence caused by runoff inflow and rain drops impacts.

\subsubsection{Biochemical Oxygen Demand}

The variation in the $\mathrm{BOD}_{5}$ of the samples is presented in Figure 8 below. The $\mathrm{BOD}_{5}$ values were higher from October to December except for the sample at the abattoir discharge point (TADP). This may be as a result of the decreased volume of water in the stream and river which no longer enjoyed the dilution from direct precipitation and runoff but was still subject to a considerable volume of wastes from the abattoir (TADP) and upstream textile industry discharges (TAUS). This pattern of variation was also obtained by Irekpita [24] on the profiling of pollution on river Kubani.

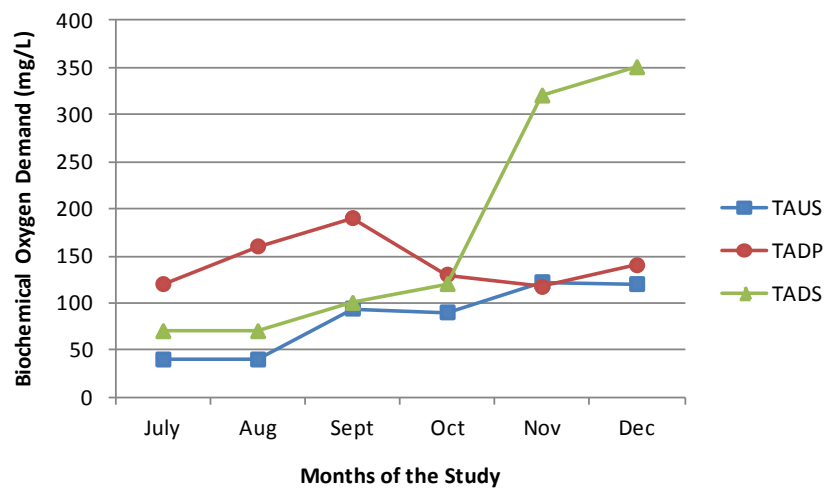

Figure 8. Biochemical oxygen demand trend during the study period

The $\mathrm{BOD}_{5}$ values of the upstream samples (TAUS) were the lowest among the three sampling points for the entire duration of the study. All the $\mathrm{BOD}_{5}$ values throughout the study period were above $20 \mathrm{mg} / \mathrm{L}$ usually allowed in rivers where the self-cleansing capacity of the river will accommodate it. This is an indication that the discharging of the abattoir waste into the river contributes significantly to the organic pollution of the river.

\subsubsection{Chemical Oxygen Demand}

The COD values obtained from the tests are presented in Figure 9 below.

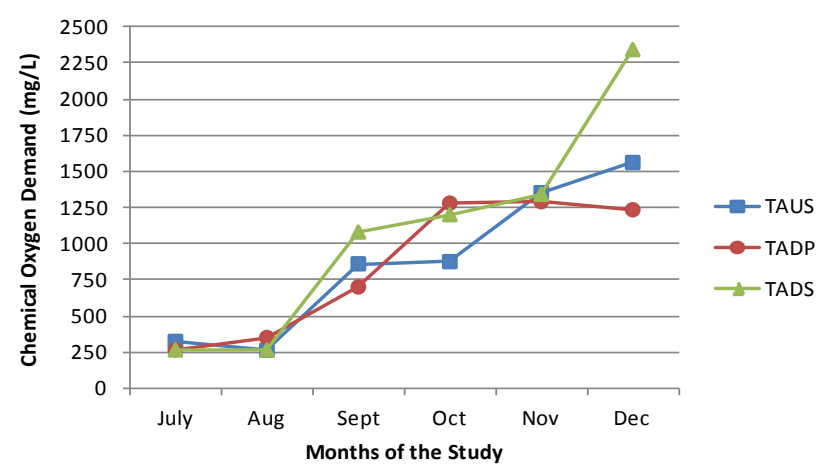

Figure 9. Variation of chemical oxygen demand 
The COD values are higher in magnitude than their corresponding $\mathrm{BOD}_{5}$ counterpart because they measure wastes which are both biodegradable and non biodegradable, hence covering a broader spectrum [25]. COD showed a similar pattern of variation as $\mathrm{BOD}_{5}$. The reasons for such variation are the same with those advanced for $\mathrm{BOD}_{5}$.

\subsubsection{Nitrate-nitrogen}

Figure 10 below presents the variation of nitrate-N during the study period. The nitrate- $\mathrm{N}$ concentrations for samples collected at the discharge point (TADP) peaked in September; lowered sharply in October and November and then began to increase again in December.

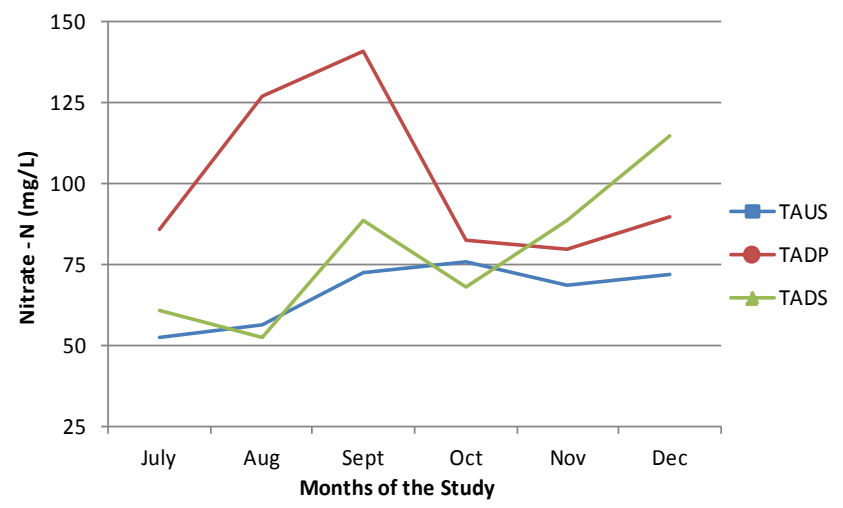

Figure 10. Nitrate-nitrogen trend during the study period

The peak in September could be due to two reasons: samples were collected under heavy rain when the sites were troubled and could have included bottom sediments, and the surface runoff inflow to the sites brought with it organic matter-laden wastewater from the catchments which may have increased the nitrate $-\mathrm{N}$ concentration at the sites. The propensity for this movement is higher when the moisture holding capacity of the soil is greatly exceeded, and this could have been the case in this area in August and September. Nitrate- $\mathrm{N}$ concentrations at all the sites in the study period were well over the $11 \mathrm{mg} / \mathrm{L} \mathrm{WHO}$ recommended limits for drinking water [23]. Nitrate has been linked with methemoglobinemia or 'blue baby syndrome' at concentrations above $50 \mathrm{mg} / \mathrm{L}$ [26] and stomach cancer in humans. Other effects include nitrate poisoning in animals and great increase of phytoplankton in a water body due to increased nutrient levels (eutrophication) which damages the ecosystem in the water body [27]. Eutrophication also increases water treatment costs. In addition, the degradation of nutrients may deplete the oxygen in the water. Moreover, the denitrification process in water produces nitrous oxide $\left(\mathrm{N}_{2} \mathrm{O}\right)$ which is a greenhouse gas [28].

\subsubsection{Ammonia-nitrogen}

Figure 11 below presents the variation of ammonianitrogen during the study period.

Ammonia- N concentration showed no regular pattern except that TADP and TADS experienced peaks in November. The concentration of ammonia-N at the upstream sample point (TAUS) was less than the other values throughout the study period. This indicates that the increased ammonia- $\mathrm{N}$ in the water is due to the abattoir wastewater discharged into the river. The elevated levels of ammonia-N in September and November are an indication of recent organic pollution. The WHO thresholds for odour and taste concentrations for ammonia are $1.5 \mathrm{mg} / \mathrm{L}$ (in alkaline $\mathrm{pH}$ ), and $35 \mathrm{mg} / \mathrm{L}$ respectively. During water treatment, the presence of ammonia- $\mathrm{N}$ is an issue as it reacts with chlorine to reduce free chlorine and to form chloramines which are less effective disinfectants. In water bodies, ammonia is also known to be toxic to fish [29].

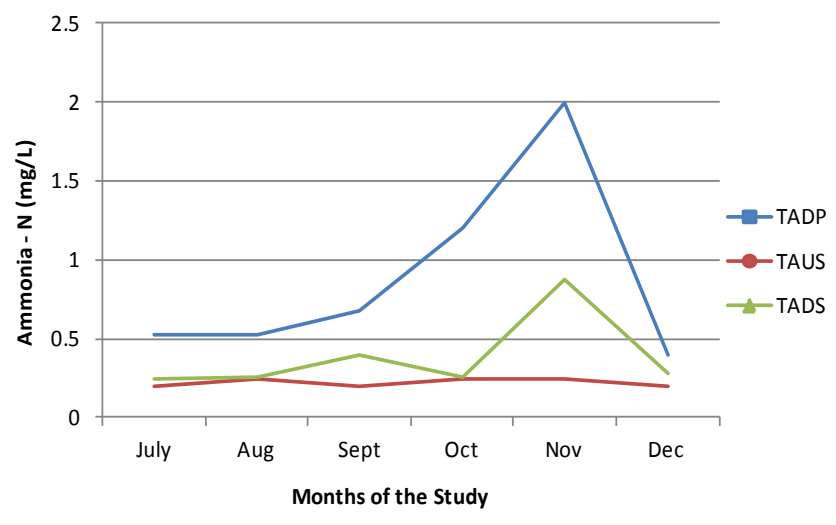

Figure 11. Variation of chemical oxygen demand

\subsubsection{Total Nitrogen}

Figure 12 below presents the variation of total nitrogen during the study period.

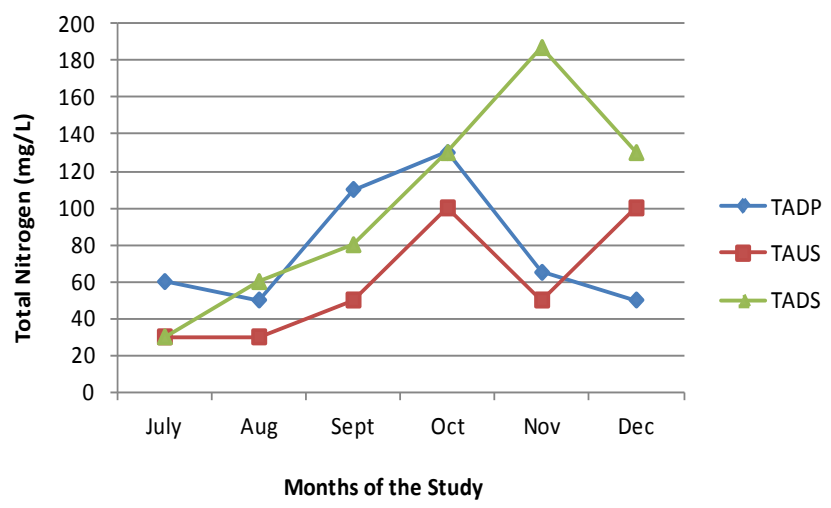

Figure 12. Variation of total nitrogen during the study period

Total nitrogen exhibited an increasing concentration from month to month up to October then TAUS and TADP dropped in November. This could be attributed to runoff inflow from the catchment area during the rainy season and the receding volume of water in the drier months which still received a considerable amount of nitrogen compounds from the abattoir wastewater.

This indicates that the livestock activities (production, marketing and processing) have negatively impacted the water sources in the area. This can lead to eutrophication in the river.

\subsubsection{Total Phosphorus}

Figure 13 below presents the variation of total phosphorus during the study period.

The concentration of total phosphorus increased progressively throughout the period of the study for all the samples. The increment in phosphorus concentration from October to December is attributable to less dilution in the river due the cessation of rainfall. The concentrations of 
phosphorus in the downstream samples were higher than the upstream samples indicating that the discharge has an impact on the river water. Phosphorus is one of the nutrients that cause eutrophication in water bodies.

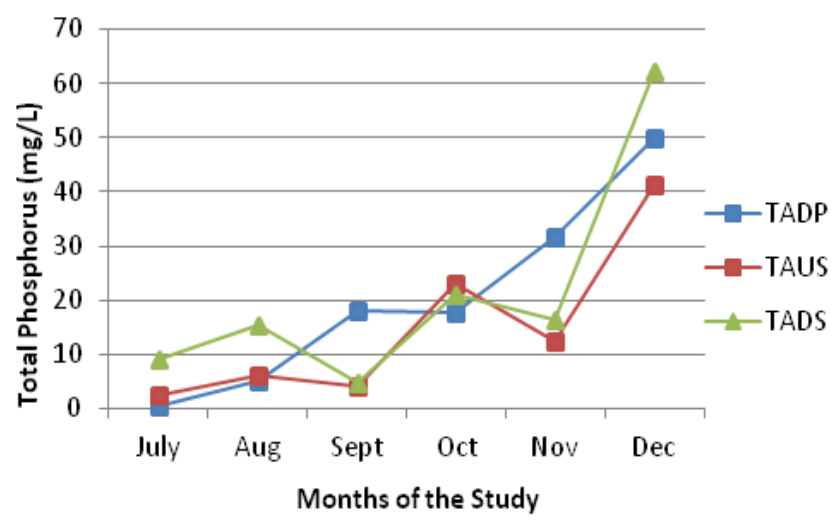

Figure 13. Total phosphorus trend during the study period

\subsubsection{Iron}

The variation of the concentration of iron is presented in Figure 14 below.

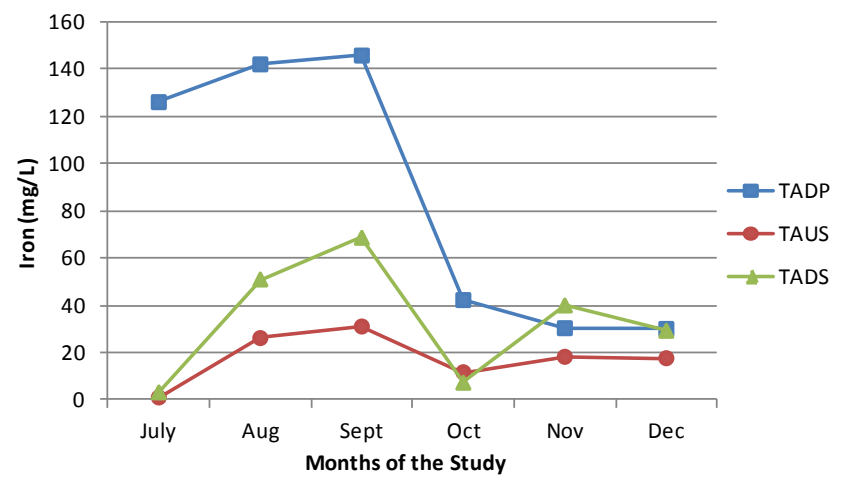

Figure 14. Variation of iron concentration during the study period

Iron exhibited a decreasing trend from September to December. This is attributable to the combined contribution of iron compounds from municipal runoff in the rainy season. The presence of iron may be due to the littering of livestock wastes around the study area. The iron may have come from animal waste since iron is an essential macro nutrient for the normal functioning of all living organisms. Though iron is beneficial in human diet at low concentrations [30], elevated concentrations produce objectionable reddish-brown colour in the water due to the oxidation of ferrous iron to ferric iron. The presence of iron at concentration above $0.3 \mathrm{mg} / \mathrm{L}$ causes staining of laundry and plumbing fixtures [23]. The levels of iron present in the river water were well above $20 \mathrm{mg} / \mathrm{L}$ and the downstream concentrations were higher than iron levels upstream, indicating an impact of the waste discharge in the water body.

\subsubsection{Zinc}

The results of zinc are presented in Figure 15 below. Zinc is an essential trace element found in almost all food; hence its source is diet.

Zinc normally occurs in low concentrations in surface water. Drinking-water become unacceptable to customers at zinc concentrations above $3 \mathrm{mg} / \mathrm{L}$ [23]. None of the samples exceeded this value during the period of the study.
This indicates that livestock activities around the sites had no influence on the surface water due to zinc.

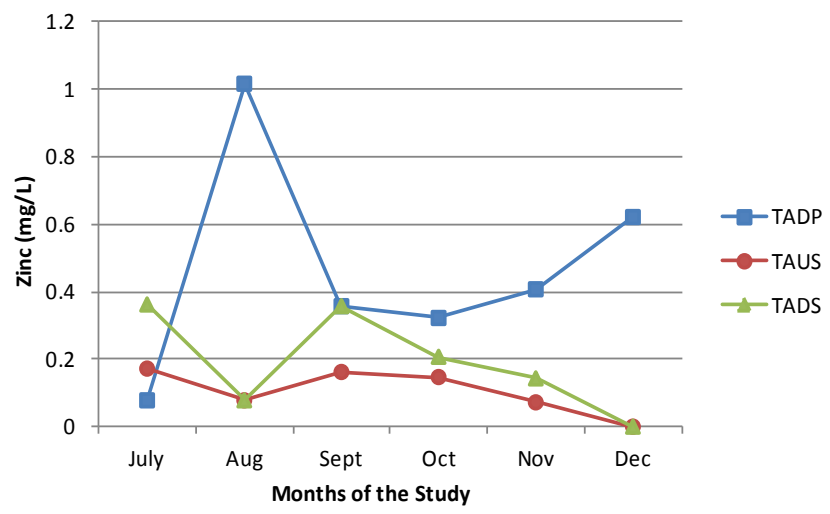

Figure 15. Zinc trend during the study period

\subsubsection{Lead}

The concentration of lead in all the samples was $0 \mathrm{mg} / \mathrm{L}$ except for TADP in November (40 mg/L) and December $(10 \mathrm{mg} / \mathrm{L})$. The reasons for the sudden high values in November and December at TADP may be due to the presence of lead in the rumen contents of cows that grazed along the high ways. An earlier study found that lead compounds were present in high concentrations in grasses and shrubs that grew along the highways [31].

\subsubsection{Cadmium}

Cadmium concentrations in the samples are presented in Figure 16 below.

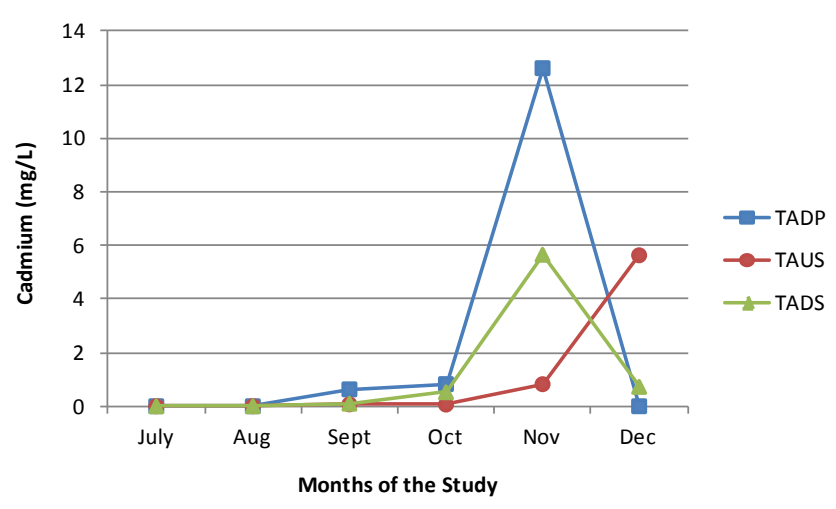

Figure 16. Cadmium variation during the study period

Cadmium was not detected in any sample until September. The appearance of cadmium can be attributed to the reduction in the dilution due to the reduced rainfall. WHO maximum allowable concentration of cadmium in drinking water is $0.003 \mathrm{mg} / \mathrm{L}$ [23]. This value was exceeded in all the samples when it started appearing.

\section{Conclusions}

The effects of abattoir wastewater discharge into river Kaduna on its water quality were assessed through water quality monitoring. Findings from this research indicate that livestock processing and marketing activities at Tudunwada Abattoir have impacted river Kaduna water quality. Concentrations of $\mathrm{BOD}_{5}, \mathrm{COD}$, nitrate-nitrogen, ammonia-nitrogen, total nitrogen and total phosphorus were in excess of normal levels for river water. The 
downstream levels of these parameters were higher than their corresponding upstream values, indicating that the discharge of the abattoir wastewater into the river has negatively impacted the river water. The dilution of the high-strength abattoir wastewater in the river water was not enough to reduce them to acceptable levels. Although there is a potential that an improvement of the water quality may be observed further downstream due to selfpurification and further dilution effects, the high levels of these parameters is a worrying issue.

This water quality data and pollution source information will be useful in identifying water quality problem areas and planning of engineering interventions. The findings can also be used as basis for legislation.

\section{Acknowledgement}

The authors wish to acknowledge the contributions of all members of staff of the Public Health Engineering Laboratory, Department of Water Resources and Environmental Engineering, Ahmadu Bello University, Zaria for their immense contributions to the success of this study.

\section{Statement of Competing Interests}

The authors have no competing interests.

\section{List of Abbreviations}

$\begin{array}{ll}\text { BOD } & \text { biochemical oxygen demand } \\ \text { BOD }_{5} & \text { 5-day biochemical oxygen demand } \\ \text { COD } & \begin{array}{l}\text { chemical oxygen demand } \\ \text { dissolved oxygen }\end{array} \\ \text { DO } & \text { Tudun Wada Abattoir discharged point } \\ \text { TADP } & \text { Tudun Wada Abattoir downstream } \\ \text { TADS } & \text { Tudun Wada Abattoir upstream } \\ \text { TAUS } & \text { total dissolved solids } \\ \text { TDS } & \text { total suspended solids } \\ \text { TSS } & \text { World Health Organization. }\end{array}$

\section{References}

[1] Zhai, X., Xia, J., and Zhang, Y., (2014). Water quality variation in the highly disturbed Huai River Basin, China from 1994 to 2005 by multi-statistical analyses. Science of The Total Environment. 496: p. 594-606.

[2] Hillel, N., Geyer, S., Licha, T., Khayat, S., Laronne, J.B., and Siebert, C., (2015). Water quality and discharge of the Lower Jordan River. Journal of Hydrology. 527: p. 1096-1105.

[3] Zhang, X., Wu, Y., and Gu, B., (2015). Urban rivers as hotspots of regional nitrogen pollution. Environmental Pollution. 205: p. 139144.

[4] Smith, V.H. and Schindler, D.W., (2009). Eutrophication science: where do we go from here? Trends in Ecology and Evolution. 24(4): p. 201-207.

[5] Badruzzaman, M., Pinzon, J., Oppenheimer, J., and Jacangelo, J.G., (2012). Sources of nutrients impacting surface waters in Florida: A review. Journal of Environmental Management. 109: p. 80-92.

[6] Jaji, M.O., Bamgbose, O., Odukoya, O.O., and Arowolo, T.A., (2007). Water quality assessment of Ogun river, South West Nigeria. Environmental Monitoring and Assessment. 133(1-3): p. 473-482.
[7] Obire, O., Ogan, A., and Okigbo, R.N., (2008). Impact of fertilizer plant effluent on water quality. International Journal of Environmental Science \& Technology. 5(1): p. 107-118.

[8] Osibanjo, O., Daso, A.P., and Gbadebo, A.M., (2011). The impact of industries on surface water quality of River Ona and River Alaro in Oluyole Industrial Estate, Ibadan, Nigeria. African Journal of Biotechnology. 10(4): p. 696-702.

[9] Arimoro, F.O., (2009). Impact of rubber effluent discharges on the water quality and macroinvertebrate community assemblages in a forest stream in the Niger Delta. Chemosphere. 77(3): p. 440-449.

[10] Kato, T., Kuroda, H., and Nakasone, H., (2009). Runoff characteristics of nutrients from an agricultural watershed with intensive livestock production. Journal of Hydrology. 368(1-4): p. 79-87.

[11] Burkholder, J., Libra, B., Weyer, P., Heathcote, S., Kolpin, D., Thome, P.S., and Wichman, M., (2007). Impacts of Waste from Concentrated Animal Feeding Operations on Water Quality. Environmental Health Perspectives. 115(2): p. 308-312.

[12] Khaleel, R., Reddy, K.R., and Overcash, M.R., (1980). Transport of potential pollutants in runoff water from land areas receiving animal wastes: A review. Water Research. 14(5): p. 421-436.

[13] Keskes, S., Hmaied, F., Gannoun, H., Bouallagui, H., Godon, J.J., and Hamdi, M., (2012). Performance of a submerged membrane bioreactor for the aerobic treatment of abattoir wastewater. Bioresource Technology. 103(1): p. 28-34.

[14] Matsumura, E.M. and Mierzwa, J.C., (2008). Water conservation and reuse in poultry processing plant-A case study. Resources, Conservation and Recycling. 52(6): p. 835-842.

[15] Akan, J.C., Abdulrahman, F.I., and Yusuf, E., (2010). Physical and Chemical Parameters in Abattoir Wastewater Sample, Maiduguri Metropolis, Nigeria. Pacific Journal of Science and Technology. 11(1): p. 640 - 648.

[16] Adeyemo, O.K., Ayodeji, I.O., and Aiki-Raji, C.O., (2002). The Water Quality and Sanitary Conditions in a Major Abattoir (Bodija) in Ibadan, Nigeria. African Journal of Biomedical Research. 5(51-55).

[17] Del Nery, V., de Nardi, I.R., Damianovic, M.H.R.Z., Pozzi, E., Amorim, A.K.B., and Zaiat, M., (2007). Long-term operating performance of a poultry slaughterhouse wastewater treatment plant. Resources, Conservation and Recycling. 50(1): p. 102-114.

[18] Omole, D.O. and Longe, E.O., (2008). An Assessment of the Impact of Abattoir Effluents on River Illo, Ota, Nigeria. Journal of Environmental Science and Technology. 1(2): p. 56-64.

[19] Mutamim, N.S.A., Noor, Z.Z., Hassan, M.A.A., Yuniarto, A., and Olsson, G., (2013). Membrane bioreactor: Applications and limitations in treating high strength industrial wastewater. Chemical Engineering Journal. 225: p. 109-119.

[20] APHA, (1998).Standard methods for the examination of water and wastewater, 20th edition. Washington: American Public Health Association (APHA).

[21] Chiappini, S.A., Kormes, D.J., Bonetto, M.C., Sacco, N., and Cortón, E., (2010). A new microbial biosensor for organic water pollution based on measurement of carbon dioxide production. Sensors and Actuators B: Chemical. 148(1): p. 103-109.

[22] Mara, D.D. and Pearson, H.W., (1987).Waste stabilization ponds: design manual for Mediterranean Europe. Copenhagen: World Health Organization, Regional Office for Europe.

[23] WHO, (2011).Guidelines for Drinking-water Quality, 4th ed. Geneva: World Health Organization.

[24] Irekpita, H., Profiling of Surface Water Pollution in Zaria, in Department of Chemistry. 2000, Ahmadu Bello University: Zaria.

[25] Han, D., Concise Environmental Engineering 1st edn. 2011.

[26] Hooda, P.S., Edwards, A.C., Anderson, H.A., and Miller, A., (2000). A review of water quality concerns in livestock farming areas. Science of The Total Environment. 250(1-3): p. 143-167.

[27] Pastén-Zapata, E., Ledesma-Ruiz, R., Harter, T., Ramírez, A.I., and Mahlknecht, J., (2014). Assessment of sources and fate of nitrate in shallow groundwater of an agricultural area by using a multi-tracer approach. Science of The Total Environment. 470471(0): p. 855-864.

[28] Haag, D. and Kaupenjohann, M., (2001). Landscape fate of nitrate fluxes and emissions in Central Europe: A critical review of concepts, data, and models for transport and retention. Agriculture, Ecosystems \& Environment. 86(1): p. 1-21.

[29] Armstrong, B.M., Lazorchak, J.M., Murphy, C.A., Haring, H.J., Jensen, K.M., and Smith, M.E., (2012). Determining the effects of ammonia on fathead minnow (Pimephales promelas) reproduction. Science of The Total Environment. 420(0): p. 127-133. 
[30] Twort, A.C., Ratnayaka, D.D., and Brandt, M.J., (2002).Water Supply. 5th ed. Oxford: Butterworth-Heinamann; copublished by IWA Publishing.
[31] Kalu, O.M., The Analysis of the Biochemical Compositions of Highway Shrubs, in Unpublished MSC Thesis, Department of Biochemistry. 1999, Ahmadu Bello University: Zaria. 